\title{
Recycling Polyurethanes through Transcarbamoylation
}

\author{
Liang Zhao and Vincent Semetey* \\ Cite This: ACS Omega 2021, 6, 4175-4183 \\ Read Online
}

ABSTRACT: In this paper, we describe a new strategy to recycle polyurethanes (PUs) using base-catalyzed transcarbamoylation. PUs were depolymerized qualitatively in the presence of $\mathrm{MeOH}$ (methanol)/tetrahydrofuran as a solvent and tert-butoxide as a base catalyst. The resulting depolymerized mixture constituted by $O$-dimethylcarbamates and polyols can either be used as the starting material to synthesize new PUs with the transcarbamoylation approach or be purified to recover polyols and diisocyanates. The versatility and easy scaling-up of the experimental procedures and high depolymerization outcomes of the presented method make this strategy very attractive for PU recycling.

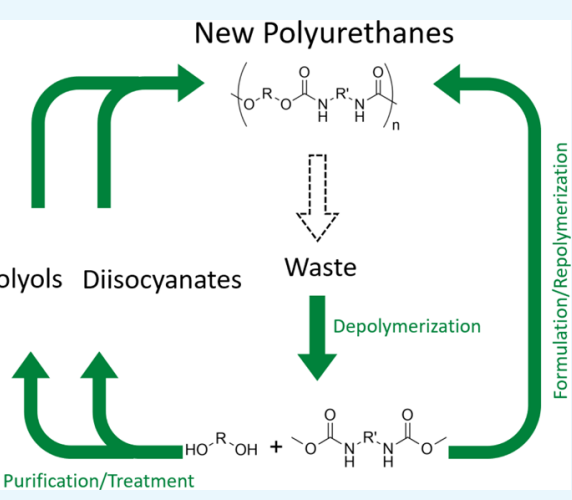

\section{INTRODUCTION}

Polyurethane (PU) is one of the most used polymers all over the world. The global production of PU was 22.9 million tons in 2017 and is increasing by $4.5 \%$ per year. ${ }^{1,2}$ As a result of the increasing quantity of PU demand, a large amount of PU waste, particularly foams, was disposed of by landfilling in the last decades. Postconsumer products as well as scraps from postproduction products reach almost $10 \%$ of the total production. ${ }^{3}$ However, increasing landfill costs, decreasing landfill space, environmental issues, and strengthening of public policies and regulations are forcing consideration of alternative options for the disposal of PU materials. PU recycling has experienced growing attention from the research and industrial world; ${ }^{4}$ recycling of any kind of plastic to convert it into valuable products is one of the main challenges of today's society.

PU recycling is an alternative approach to landfilling. There are three kinds of strategies: (i) physical recycling (corresponding to the mechanical transformation of $\mathrm{PU}$ foams into flakes, granules, or powder to be used in new materials production); (ii) energy recovery (conversion of PU waste materials into useable heat, electricity, or fuel), and (iii) chemical recycling (consisting of the transformation of polymer chains into valuable chemicals). ${ }^{3}$ Several processes have been developed to chemically recycle PU foams, such as hydrolysis $^{3,5-7}$ (the first process developed to recycle PU waste in a chemical way, in particular for flexible PU foams), aminolysis $^{8-10}$ (the polymer chain is degraded with low molecular-weight amines), phosphorolysis ${ }^{11-19}$ (a reaction analogous to hydrolysis in which esters of phosphonic or phosphoric acids perform in a similar way to that of water with the formation of a phosphate), and glycolysis ${ }^{20-29}$ (the PU chain is fragmented by glycols producing polyols). Meth- anolysis of PU foams was also investigated by several groups, $^{30,31}$ starting from commercially available PU foams and thermoplastic PU (TPU) elastomer. However, the depolymerization of $\mathrm{PU}$ operated at high temperatures (above $200{ }^{\circ} \mathrm{C}$ ) with supercritical methanol limits its development.

The development of sustainable alternative and environmentally friendly routes to recyclable materials is of great interest, especially when recycling processes are able to obtain the basic valuable chemicals or building blocks which can be reused in the synthesis of chemical material or in the petrochemical industry. In this context, the transcarbamoylation reaction is an interesting reaction, allowing the conversion of a carbamate to another carbamate (Figure 1). Several metal catalysts are known to be able to activate the carbonyl group and catalyze transcarbamoylation, ${ }^{32,33}$ such as titanium(IV) isopropoxide, $^{34}$ lanthanum(III) salts, ${ }^{35,36}$ dihalodistannoxanes, ${ }^{35}$ zinc acetate ${ }^{36}$ or bismuth triflate, ${ }^{37}$ inorganic or organic

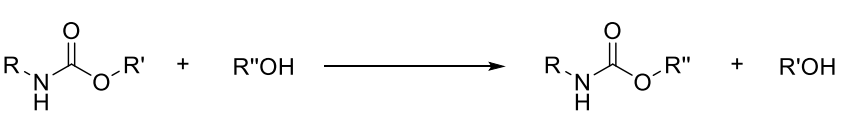

Figure 1. Transcarbamoylation reaction of a carbamate $\left(R, R^{\prime}=\right.$ aliphatic or aromatic group and $\mathrm{R}^{\prime \prime}=$ aliphatic group).

Received: October 4, 2020

Accepted: December 17, 2020

Published: February 3, 2021 
bases such as 1,5,7-triazabicyclo[4.4.0]dec-5-ene (TBD), ${ }^{38}$ and even without any catalyst with sulfonyl carbamates. ${ }^{39}$

Transcarbamoylation can be used as well to synthesize PUs to avoid the use of toxic isocyanates. ${ }^{40-43}$ Recent works have shown that transcarbamoylation is an efficient reaction and can be operated in mild conditions with a soft base at low temperatures $\left(<70{ }^{\circ} \mathrm{C}\right)$ offering promising perspectives in the field of PU recycling. ${ }^{38}$ Here, we investigate a recycling procedure involving the depolymerization of PU wastes producing dicarbamates and polyols coupled to the repolymerization of these intermediates to regenerate new PUs both using transcarbamoylation reaction in mild conditions (Figure $2) .^{38}$ The key intermediate in this strategy is the $O$ -

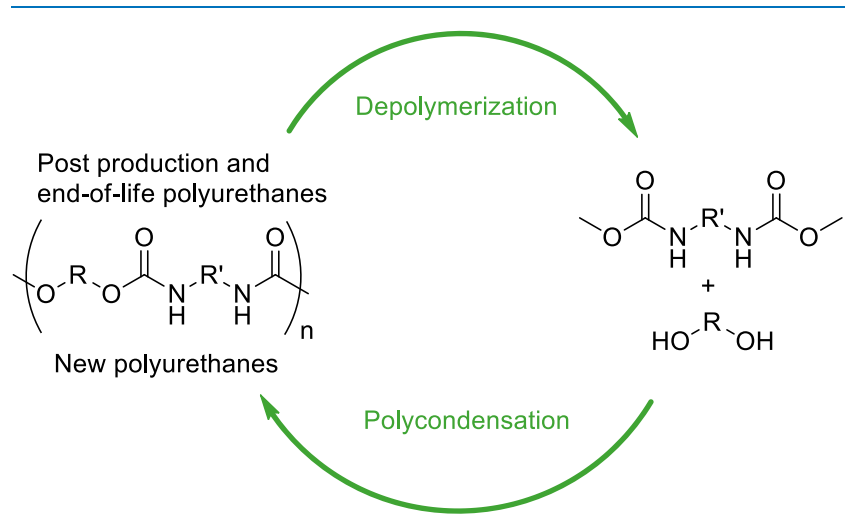

Figure 2. Recycling of PUs through transcarbamoylation.

dimethylcarbamate obtained from the complete depolymerization of PU through transcarbamoylation in the presence of methanol (namely methanolysis). This $\mathrm{O}$-dimethylcarbamate is stable to be reformulated or isolated and reactive enough to form a new urethane bond with the elimination of $\mathrm{MeOH}$ allowing the regeneration of PU.

\section{MATERIALS AND METHODS}

All solvents used were dry solvents purchased from SigmaAldrich. All reagents were purchased from Sigma-Aldrich and used without further purification. ${ }^{1} \mathrm{H}$ NMR spectra were recorded with a Bruker Avance III $(400 \mathrm{MHz})$. DMSO- $d_{6}$ or $\mathrm{CDCl}_{3}$ was used as the solvent and tetramethylsilane as the internal standard. Chemical shifts $(\delta)$ and coupling constants $(J)$ are given in parts per million and in hertz, respectively. High-performance liquid chromatography (HPLC) was monitored using an HP Agilent 1050 series HPLC with a diode array detector. HPLC analysis was performed on a Vydac $218 \mathrm{TP}$ column $(\mathrm{C} 18,5 \mu \mathrm{m}, 4.6 \mathrm{~mm}$ i.d. $\times 250 \mathrm{~mm})$ by using a linear gradient of $\mathrm{A}$ [0.1\% trifluoroacetic acid (TFA) in $\mathrm{H}_{2} \mathrm{O}$ ] and $\mathrm{B}$ ( $\mathrm{MeCN}$ containing $0.1 \%$ TFA) at a flow rate of $1.0 \mathrm{~mL} / \mathrm{min}$ with UV detection at $254 \mathrm{~nm}$. All solvents were HPLC grade. The volume of the sample injected was set at 5 $\mu \mathrm{L}$. The molecular weights $\left(M_{\mathrm{w}}\right)$ and molecular weight distributions of polymers (polydispersity index) were evaluated by size exclusion chromatography (SEC) using an Agilent 1260 Infinity Series GPC (ResiPore $3 \mu \mathrm{m}, 300 \times 7.5 \mathrm{~mm}$ ), 1.0 $\mathrm{mL} / \mathrm{min}$, UV $(250 \mathrm{~nm}$ ), and refractive index (PLGPC 220) detector. All measurements were performed with tetrahydrofuran (THF) as the eluent at a flow rate of $1.0 \mathrm{~mL} / \mathrm{min}$ at 35 ${ }^{\circ} \mathrm{C}$. Monodisperse poly(styrene) polymers were used as calibration standards. Attenuated total reflection-IR was used to characterize the infrared absorption spectra of PU samples. The infrared spectra were recorded on a Nicolet Magna 550 spectrometer equipped with a diamond probe.

Synthesis of Model O-Dibutylcarbamates $\mathbf{1 a}$ and $\mathbf{1 b}$. Diisocyanate [methylene diphenyl $4,4^{\prime}$-diisocyanate (MDI) or 1,6-diisocyanatohexane (HMDI)] (16 mmol) was added to 40 $\mathrm{mL}$ of dry 1-butanol at ambient temperature slowly. Dibutyltin dilaurate $(10 \mu \mathrm{L}, 0.016 \mathrm{mmol})$ was added, and the reaction mixture was stirred at $50{ }^{\circ} \mathrm{C}$ for $3 \mathrm{~h}$. The 1-butanol was evaporated under reduced pressure to give a white solid. The residue was purified by silica column chromatography eluting with hexane/ethyl acetate EtOAc (75/25). The fractions were concentrated under reduced pressure to give the product 1 (Figure S1). O-Dibutylcarbamate 1a: white solid (5.8 g, 91\% yield). ${ }^{1} \mathrm{H}$ NMR (400 MHz, chloroform- $d$ ): $\delta 7.31-7.26(\mathrm{~m}$, $4 \mathrm{H}), 7.12-7.07(\mathrm{~m}, 4 \mathrm{H}), 6.59-6.51(\mathrm{~m}, 2 \mathrm{H}), 4.15(\mathrm{t}, J=6.7$ $\mathrm{Hz}, 4 \mathrm{H}), 3.88(\mathrm{~s}, 2 \mathrm{H}), 1.69-1.62(\mathrm{~m}, 4 \mathrm{H}), 1.46-1.35(\mathrm{~m}$, $4 \mathrm{H})$, and $0.95(\mathrm{t}, J=7.4 \mathrm{~Hz}, 6 \mathrm{H})$. O-Dibutylcarbamate $1 \mathrm{~b}$ : white solid (6.2 g, 95\% yield). ${ }^{1} \mathrm{H}$ NMR (400 MHz, DMSO$\left.d_{6}\right): \delta 6.98-6.86(\mathrm{~m}, 2 \mathrm{H}), 3.97-3.83(\mathrm{~m}, 4 \mathrm{H}), 3.50-3.41(\mathrm{~m}$, $2 \mathrm{H}), 1.69$ (dd, $J=39.9,12.7 \mathrm{~Hz}, 4 \mathrm{H}), 1.56-1.19(\mathrm{~m}, 20 \mathrm{H})$, $1.19-1.03(\mathrm{~m}, 4 \mathrm{H})$, and $0.89-0.84(\mathrm{~m}, 6 \mathrm{H})$.

Synthesis of Model O-Dimethylcarbamates $2 \mathrm{a}-\mathrm{e}$. Diisocyanate [MDI, hexamethylene diisocyanate (HDI), HMDI, 2,6-tolylene diisocyanate (2,6-TDI), or 2,4-tolylene diisocyanate (2,4-TDI) ] ( $5 \mathrm{mmol}$ ) was added to $10 \mathrm{~mL}$ of dry methanol at ambient temperature slowly. Dibutyltin dilaurate ( $5 \mu \mathrm{L}, 0.008 \mathrm{mmol}$ ) was added, and the reaction mixture was stirred at $50{ }^{\circ} \mathrm{C}$ for $3 \mathrm{~h}$. Methanol was evaporated under reduced pressure to give a white solid. The residue was purified by silica column chromatography eluting with hexane/EtOAc $(75 / 25)$. The fractions were concentrated under reduced pressure to give the corresponding desired product $2 \mathbf{a}-\mathbf{e}$ (Figure S2). O-Dimethylcarbamate 2a: white solid (1.52 g, $97 \%$ yield). ${ }^{1} \mathrm{H}$ NMR (400 MHz, DMSO- $\left.d_{6}\right): \delta 9.52(\mathrm{~s}, 2 \mathrm{H})$, $7.33(\mathrm{~d}, J=8.2 \mathrm{~Hz}, 4 \mathrm{H}), 7.12-7.04(\mathrm{~m}, 4 \mathrm{H}), 3.77(\mathrm{~s}, 2 \mathrm{H})$, and $3.62(\mathrm{~s}, 6 \mathrm{H})$. O-Dimethylcarbamate $2 \mathrm{~b}$ : white solid $(1.45 \mathrm{~g}$, $89 \%$ yield). ${ }^{1} \mathrm{H}$ NMR (400 MHz, DMSO- $\left.d_{6}\right): \delta 7.05-6.96(\mathrm{~m}$, $2 \mathrm{H}), 3.05-3.45(\mathrm{~m}, 8 \mathrm{H}), 1.71(\mathrm{dd}, J=40.5,12.8 \mathrm{~Hz}, 4 \mathrm{H})$, $1.54-1.38(\mathrm{~m}, 8 \mathrm{H})$, and $1.30-1.05(\mathrm{~m}, 8 \mathrm{H})$. O-Dimethylcarbamate 2c: white solid (1.04 g, 90\% yield). ${ }^{1} \mathrm{H}$ NMR (400 $\left.\mathrm{MHz}, \mathrm{DMSO}-d_{6}\right): \delta 7.09-7.01(\mathrm{~m}, 2 \mathrm{H}), 3.49(\mathrm{~s}, 6 \mathrm{H}), 2.95-$ $2.90(\mathrm{~m}, 4 \mathrm{H}), 1.38-1.31(\mathrm{~m}, 4 \mathrm{H})$, and $1.23-1.19(\mathrm{~m}, 4 \mathrm{H}) . \mathrm{O}-$ Dimethylcarbamate $2 \mathrm{~d}$ : white solid (1.14 g, 96\% yield). ${ }^{1} \mathrm{H}$ NMR (400 MHz, DMSO- $\left.d_{6}\right): \delta 8.91(\mathrm{~s}, 2 \mathrm{H}), 7.13$ (d, $J=1.6$ $\mathrm{Hz}, 3 \mathrm{H}), 3.64(\mathrm{~s}, 6 \mathrm{H})$, and $2.04(\mathrm{~s}, 3 \mathrm{H})$. O-Dimethylcarbamate 2e white solid (1.15 g, 97\% yield). ${ }^{1} \mathrm{H}$ NMR (400 MHz, DMSO- $\left.d_{6}\right): \delta 9.53(\mathrm{~s}, 1 \mathrm{H}), 8.79(\mathrm{~s}, 1 \mathrm{H}), 7.48(\mathrm{~d}, J=2.2 \mathrm{~Hz}$, $1 \mathrm{H}), 7.18-7.13(\mathrm{~m}, 1 \mathrm{H}), 7.07-7.03(\mathrm{~m}, 1 \mathrm{H}), 3.63(\mathrm{~d}, J=1.8$ $\mathrm{Hz}, 6 \mathrm{H})$, and $2.10(\mathrm{~s}, 3 \mathrm{H})$.

Methanolysis of $O$-Dibutyldicarbamate 1 . The urethane $1(0.224 \mathrm{mmol})$ was dissolved in methanol $(2 \mathrm{~mL})$. A base [NaOH, KOH, LiOH, NaH, 1,8-diazabicyclo[5.4.0]undec-7-ene (DBU), TBD, tert-butoxide ( $t$-BuOK), 1.0-2.0 equiv per urethane group] was added, and the reaction mixture was heated at 55 or $65{ }^{\circ} \mathrm{C}$ with continuous agitation for $20 \mathrm{~h}$. The solvent was evaporated, and water $(15 \mathrm{~mL})$ was added and extracted with EtOAc $(3 \times)$. The combined organic layers were washed with brine, dried on magnesium sulfate, and the solvent was evaporated. The residue was purified by silica column chromatography eluting with hexane/EtOAc (75/25). The fractions were concentrated under reduced pressure to give the product 2 . 
Table 1. Optimization of the Transcarbamoylation Reaction Conditions ${ }^{a}$

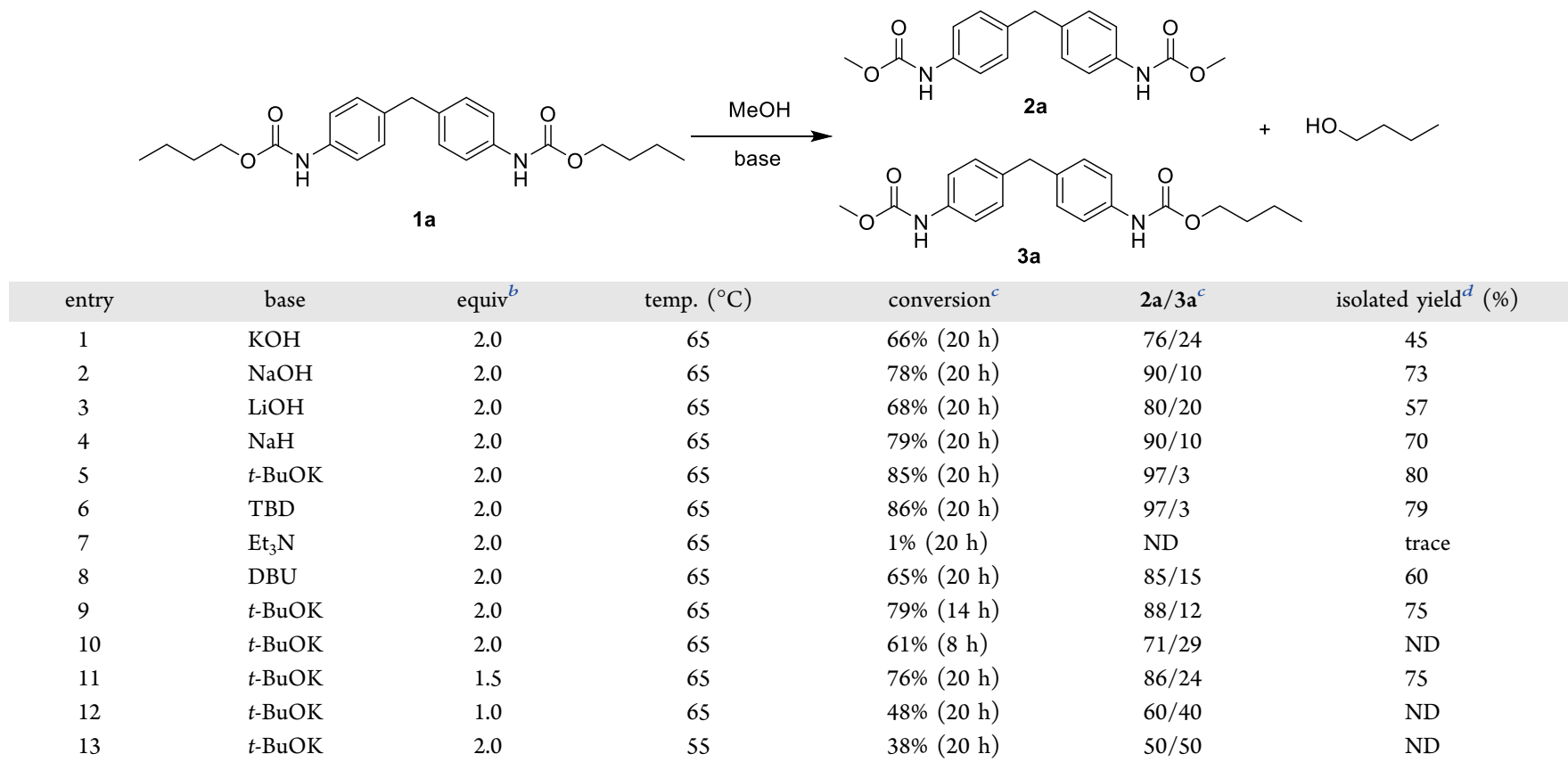

${ }^{a}$ Reactions were run with $0.224 \mathrm{mmol}$ of 1 in $2 \mathrm{~mL}$ of $\mathrm{MeOH}$ with $0.448,0.672$, or $0.896 \mathrm{mmol}$ of base for $8-20 \mathrm{~h}$ at 55 or $65^{\circ} \mathrm{C}$. ${ }^{b} \mathrm{Equivalent}$ per urethane group. ${ }^{c}$ Conversion of compound 2a group determined by LC/MS analysis of the crude products. ${ }^{d}$ Isolated yield (by column chromatography) of compound 2a. ND: not determined.

General Procedure for the Depolymerization of PU

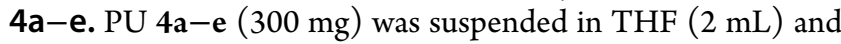
methanol $(2 \mathrm{~mL}), 2.0-2.7$ equiv per carbamate group of $t$ $\mathrm{BuOK}$ was added to the solution, and the solution was kept at continuous agitation under $65{ }^{\circ} \mathrm{C}$ for $20 \mathrm{~h}$. The solvent was then evaporated, and water $(20 \mathrm{~mL})$ was added to the reaction mixture and extracted with EtOAc $(3 \times)$. The combined organic layers were washed with brine, dried on magnesium sulfate, and the solvent was evaporated. The residue was purified by silica column chromatography with hexane/EtOAc $(75 / 25)$. The fractions were concentrated under reduced pressure to give the product $2 \mathbf{a}-\mathbf{e}$.

Optimization of Transcarbamoylation-Based Polycondensation 2a-e with PTMO. O-Dimethylcarbamate 2 (0.235 mmol), PTMO 2000 (450 mg, $0.224 \mathrm{mmol}$ ), and TBD (10 mg, $0.07 \mathrm{mmol}$ ) were added to $10 \mathrm{~mL}$ of dry toluene. The temperature was progressively increased to $130{ }^{\circ} \mathrm{C}$ under nitrogen flow (to remove $\mathrm{MeOH}$ ) and stirring. Then, the polymerization reaction was conducted over $16 \mathrm{~h}$. Finally, after it was cooled to room temperature, the obtained PU $\mathbf{4 a - e}$ was solubilized in THF and precipitated in cooled methanol.

General Procedure to Recycle TPU (Pellethane 236380AE). Pellethane 2363-80AE (300 mg) was suspended in THF $(3 \mathrm{~mL})$ and methanol $(3 \mathrm{~mL}), t$-BuOK $(60 \mathrm{mg}, 0.54$ mmol) was added to the solution, with continuous agitation under $65{ }^{\circ} \mathrm{C}$ for $20 \mathrm{~h}$; the solvent was evaporated, and water $(20 \mathrm{~mL})$ was added to the reaction mixture and extracted with EtOAc $(3 x)$. The combined organic layers were washed with brine and dried on magnesium sulfate, and the solvent was evaporated. The residue was dissolved in dry toluene $(20 \mathrm{~mL})$, with a nitrogen inlet, monomer $2(9 \mathrm{mg}, 0.03 \mathrm{mmol})$, and TBD (10 $\mathrm{mg}, 0.07 \mathrm{mmol}$ ) added to the solution; the temperature was progressively increased to $130{ }^{\circ} \mathrm{C}$ under nitrogen flow (to remove $\mathrm{MeOH}$ ) and stirring. Then, the polymerization reaction was conducted over $16 \mathrm{~h}$. Finally, after it was cooled to room temperature, the obtained PU was solubilized in THF and precipitated in methanol to get regenerated PU (220 mg, yield: 74\%).

\section{RESULT AND DISCUSSION}

We first investigated the reactivity of transcarbamoylation. Dibutyl(methylenebis(4,1-phenylene))dicarbamate 1a was chosen as the model substrate for aromatic carbamates to optimize reaction conditions including bases, temperatures, and reaction times. The results are summarized in Table 1 . According to the previous work carried out by our group, ${ }^{38}$ we first used 2 equiv per urethane group of potassium hydroxide $(\mathrm{KOH})$ as the base at $65{ }^{\circ} \mathrm{C}$ in the presence of methanol (Table 1, entry 1 ). The reaction afforded a mixture of compounds 1a, 2a, and 3a (detected by HPLC) conducting a yield of $45 \%$ in disubstituted dicarbamate $2 a$. In order to increase the yield of the compound $\mathbf{2 a}$, other inorganic bases such as sodium hydroxide $(\mathrm{NaOH})$, lithium hydroxide $(\mathrm{LiOH})$, and sodium hydride $(\mathrm{NaH})$ as well as organic bases such as potassium $t$-BuOK; TBD, triethylamine $\left(\mathrm{Et}_{3} \mathrm{~N}\right)$, and DBU (Table 1, entries 2-8) were screened. Most of the bases evaluated $(\mathrm{NaOH}, \mathrm{KOH}, \mathrm{LiOH}, \mathrm{NaH}, \mathrm{DBU}, \mathrm{TBD}$, and $t$ $\mathrm{BuOK}$ ) afforded dimethylcarbamates with good conversions. It was shown that the reaction is base-dependent, $t$-BuOK and TBD providing the highest yield ( 80 and $79 \%$ respectively). The impact of the reaction time (Table 1, entries 5, 9, and 10), equivalent of base (Table 1, entry 5, and entries 11-12), and reaction temperature (Table 1 , entry 5, and entry 13) was studied. The yield of $\mathbf{2 a}$ decreased with the reduction of reaction time or the amount of base. The best condition is 2 equiv of potassium $t$ - $\mathrm{BuOK}$ as the base at $65{ }^{\circ} \mathrm{C}$ reacted for 20 $\mathrm{h}$ (Table 1, entry 5) and was kept for the rest of the study. Furthermore, the reactivity of aliphatic diurethane with the use of the dicarbamate $\mathbf{1 b}$ as model substrate of aliphatic PU was also investigated resulting in the same observations (see the 
Table 2. Depolymerization of PUs ${ }^{a}$

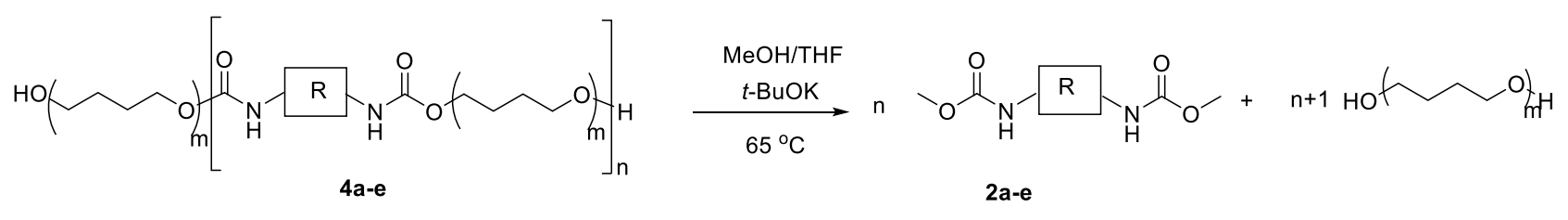

$\mathrm{R}=$<smiles>CCc1ccc(Cc2ccc(C)cc2)cc1</smiles>

a<smiles>CCC1CCC(CC2CCC(C)CC2)CC1</smiles>

b<smiles>CCCCCCCC</smiles><smiles>CCc1cccc(I)c1C</smiles>

d<smiles>[Y]c1ccc(C)c(C)c1</smiles>

\begin{tabular}{|c|c|c|c|c|c|c|c|}
\hline entry & 4 & $n$ & $m$ & $M_{\mathrm{w}}$ & $t$-BuOK (equiv) ${ }^{b}$ & conversion $^{c}(\%)$ & isolated yield $^{d}(\%)$ \\
\hline 1 & $4 a$ & 5 & 14 & 6500 & 2.0 & 79 & 75 \\
\hline 2 & $4 b$ & 5 & 14 & 5250 & 2.0 & 65 & 53 \\
\hline 3 & $4 c$ & 6 & 14 & 8200 & 2.0 & 71 & 63 \\
\hline 4 & $4 d$ & 3 & 14 & 4700 & 2.0 & 78 & 74 \\
\hline 5 & $4 e$ & 4 & 14 & 5900 & 2.0 & 78 & 65 \\
\hline 6 & $4 a$ & 8 & 27 & 20,000 & 2.0 & 77 & 73 \\
\hline 7 & $4 a$ & 11 & 27 & 28,000 & 2.0 & 81 & 78 \\
\hline 8 & $4 a$ & 10 & 40 & 33,600 & 2.0 & 78 & 70 \\
\hline 9 & $4 a$ & 11 & 27 & 28,000 & 2.3 & 90 & 85 \\
\hline 10 & $4 a$ & 11 & 27 & 28,000 & 2.5 & 83 & 83 \\
\hline 11 & $4 a$ & 11 & 27 & 28,000 & 2.7 & 85 & 81 \\
\hline
\end{tabular}

${ }^{a} 300 \mathrm{mg}$ of PU was suspended in $4 \mathrm{~mL}$ of solvent ( $\left.\mathrm{MeOH} / \mathrm{THF}, 1 / 1\right)$, stirred at $65^{\circ} \mathrm{C}$, and $t$-BuOK was added then reacted for $20 \mathrm{~h} .{ }^{b} \mathrm{Equivalent}$ per urethane group. ${ }^{c}$ Determined by ${ }^{1} \mathrm{H}$ NMR analysis of the crude products. ${ }^{d}$ Isolated yield (by column chromatography) of dicarbamate 2 .

Table 3. Optimization of Transcarbamoylation-Based Polycondensation ${ }^{a}$

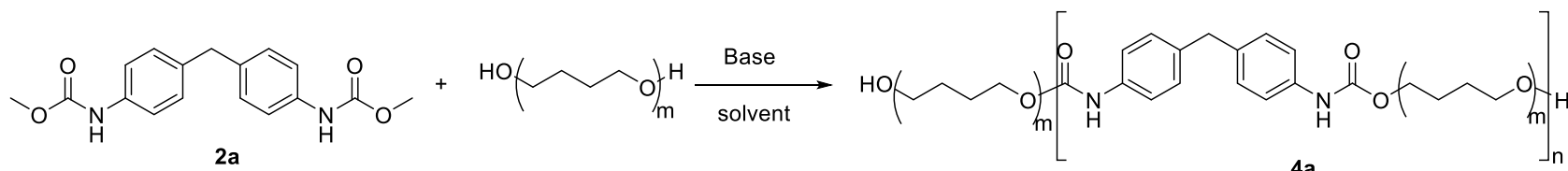

\begin{tabular}{|c|c|c|c|c|c|c|c|c|}
\hline entry & 2a (equiv) & base (equiv) & temp. $\left({ }^{\circ} \mathrm{C}\right)$ & reaction times $(\mathrm{h})$ & solvent & $M_{\mathrm{w}}(\mathrm{g} / \mathrm{mol})^{b}$ & $M_{\mathrm{w}} / M_{\mathrm{n}}^{b}$ & yield (\%) \\
\hline 1 & 1.0 & TBD (0.05) & 130 & 8 & & 6600 & 1.11 & trace \\
\hline 2 & 1.0 & TBD (0.05) & 130 & 8 & toluene & 8900 & 1.21 & 35 \\
\hline 3 & 1.0 & TBD (0.15) & 130 & 8 & toluene & 11,200 & 1.31 & 33 \\
\hline 4 & 1.0 & TBD $(0.25)$ & 130 & 8 & toluene & 11,200 & 1.51 & 34 \\
\hline 5 & 1.0 & TBD (0.15) & 130 & 16 & toluene & 11,200 & 1.38 & 54 \\
\hline 6 & 1.0 & TBD (0.15) & 150 & 16 & toluene & 11,200 & 1.55 & 56 \\
\hline 7 & 1.1 & TBD (0.15) & 130 & 16 & toluene & 15,800 & 1.35 & 55 \\
\hline 8 & 1.2 & TBD $(0.15)$ & 130 & 16 & toluene & 15,800 & 1.41 & 51 \\
\hline 9 & 1.1 & TBD (0.15) & 130 & 20 & toluene & 13,500 & 1.53 & 57 \\
\hline 10 & 1.1 & $t$-BuOK $(0.15)$ & 130 & 16 & toluene & 8900 & 1.45 & 52 \\
\hline 11 & 1.1 & TBD (0.05) & reflux & 16 & THF & 4300 & 1.08 & trace \\
\hline
\end{tabular}

${ }^{a}$ Reactions were performed under nitrogen flow with $0.224,0.235$, or $0.269 \mathrm{mmol}$ diurethane $2 \mathrm{a}, 0.05-0.25$ equiv per urethane group of TBD, and $0.224 \mathrm{mmol}$ PTMO in $10 \mathrm{~mL}$ of anhydrous toluene or THF with corresponding base at appropriate reaction time and temperature. ${ }^{b}$ Determined by SEC.

Supporting Information, Table S1 for details). It is noteworthy that in our trials no byproducts such as aromatic amines were detected by liquid chromatography/mass spectrometry (LC/ MS) due to the mild reaction conditions used. The excellent reactivity of aromatic and aliphatic dicarbamates subjected to transcarbamoylation reaction with methanol is consequently particularly interesting to develop depolymerization strategies of PU in mild conditions.

After the optimization of the transcarbamoylation reaction with the model dicarbamates, several PUs were synthesized to perform transcarbamoylation-based depolymerizations. PUs obtained from different diisocyanates (see the Supporting
Information) were reacted with $t$ - $\mathrm{BuOK}$ using methanol $(\mathrm{MeOH})$ and THF as solvents at $65{ }^{\circ} \mathrm{C}$ to produce the corresponding $\mathrm{O}$-dimethylcarbamate and polytetrahydrofuran (PTMO). The results are shown in Table 2. Two equivalents of a base were used as the standard, and 5 different PUs (4a4e) which are widely used in PU industry were chosen (Table 2 , entries $1-5$ ) to investigate the depolymerization by the described process. For all those PUs, depolymerization was observed affording the corresponding $O$-dimethylcarbamates $(\mathbf{2 a}-\mathbf{2 e})$ regardless of the chemical structure of the PUs (Table 2, entry 1-5) and their molecular weights (conversion ranging from $77-81 \%$; Table 2 , entries 1 and $6-8$ ). It is worth 
Table 4. Recycling PUs through Depolymerization and Polycondensation ${ }^{a}$

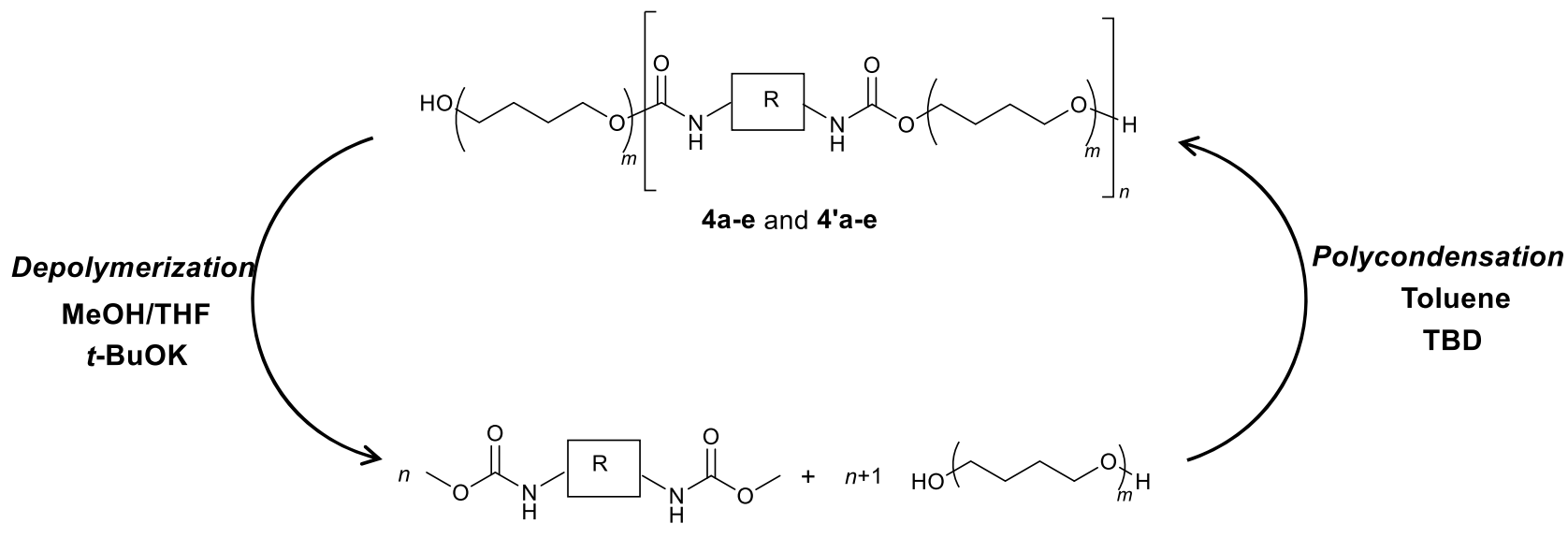

2a-e

$\mathrm{R}=$<smiles>CCc1ccc(Cc2ccc(C)cc2)cc1</smiles>

a<smiles>CCC1CCC(CC2CCC(C)CC2)CC1</smiles>

b

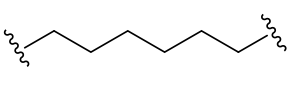

c<smiles>Cc1cccc(C)c1C</smiles>

d

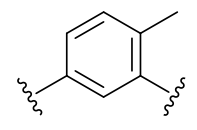

e

\begin{tabular}{|c|c|c|c|c|c|c|c|c|c|}
\hline \multirow[b]{2}{*}{ entry } & \multicolumn{5}{|c|}{ depolymerization of PU into monomers } & \multicolumn{4}{|c|}{ repolymerized PU } \\
\hline & 4 & $\mathrm{R}$ & $M_{\mathrm{w}} / M_{\mathrm{n}}^{b, f}$ & $M_{\mathrm{w}}^{b}$ & yield $(\%)^{c}$ & $4^{\prime}$ & $M_{\mathrm{w}}^{d, f}$ & $M_{\mathrm{w}} / M_{\mathrm{n}}^{d^{\prime} f}$ & yield $(\%)^{e}$ \\
\hline 1 & $4 a$ & $2 a$ & 1.21 & 28,000 & 85 & $4^{\prime} a$ & 18,100 & 1.34 & 51 \\
\hline 2 & $4 b$ & $2 b$ & 1.24 & 28,000 & 73 & $4^{\prime} \mathrm{b}$ & 10,800 & 1.30 & 31 \\
\hline 3 & $4 c$ & $2 c$ & 1.24 & 22,000 & 89 & $4^{\prime} \mathrm{c}$ & 13,000 & 1.35 & 65 \\
\hline 4 & $4 d$ & $2 d$ & 1.38 & 14,000 & 91 & $4^{\prime} \mathrm{d}$ & 8900 & 1.42 & 56 \\
\hline 5 & $4 e$ & $2 e$ & 1.33 & 20,000 & 81 & $4^{\prime} \mathrm{e}$ & 10,000 & 1.33 & 41 \\
\hline
\end{tabular}

${ }^{a}$ Depolymerization conditions as described in Table 2. Polymerization: the same process as described in Table 3 (with extra 0.1 equiv of monomer 2). ${ }^{b} \mathrm{PU}$ synthesized by diisocyanate approach. ${ }^{c}$ Isolated yield (monomer 2 , by column chromatography) of depolymerization, calculated for the urethane group. ${ }^{d} \mathrm{PU}$ synthesized by transcarbamoylation. ${ }^{e}$ Yield of polymerization. ${ }^{f}$ Determined by SEC.

noting that with the increase of the amount of the base, the conversion rate and yield were improved, leading to the obtention of monomer $\mathbf{2 a}$ with high yields. We first optimized the base catalysis conditions (Table 2, entries 7 and 9-11). The best amount of $t$-BuOK was found to be 2.3 equiv (Table 2, entry 9). A remarkable fact is that THF can be substituted by $\mathrm{MeOH}$ by just increasing reaction times (THF being a good swelling solvent): for example, PU $4 a\left(M_{\mathrm{w}}=6500 \mathrm{~g} / \mathrm{mol}, 300\right.$ $\mathrm{mg}$ ) reacted in $4 \mathrm{~mL}$ of $\mathrm{MeOH}$ at $65^{\circ} \mathrm{C}$ for $20 \mathrm{~h}$ leads to $2 \mathrm{a}$ with a $73 \%$ yield.

One important advantage of methanolysis is the production of $O$-methylcarbamate, a useful reactive intermediate that can be used to regenerate PUs through transcarbamoylation associated to the release of $\mathrm{MeOH}$ which can be easily eliminated by evaporation during the reaction. ${ }^{40-42}$ We tried to achieve repolymerization to prepare $\mathrm{PU}$ by using the dicarbamate 2a and PTMO (2000); they were subjected to transcarbamoylation, with an organic base TBD to catalyze the reaction. ${ }^{43}$ The results are shown in Table 3. We first tried a solvent-free condition; however, only a trace amount of PU was observed (Table 3, entry 1) possibly due to its poor solubility in liquid PTMO (2000). A solvent is required to observe the formation of PU, and toluene was therefore chosen as the solvent for the rest of the study (Table 3, entries 2-10). The effect of the quantity of base (TBD) to catalyze the reaction was then studied. When 0.15 and 0.25 equiv per urethane group of base were used (Table 3, entries 3 and 4), the molecular weights and yields increased. As expected, the increase of the reaction time improved the polymerization yield (from 33 to 54\%) (Table 3, entries 3 and 5), while there was no noticeable improvement under a higher reaction temperature (Table 3, entry 6). The use of an excess of dicarbamate improves polycondensation: 1.1 and 1.2 equiv have been tested, leading fortunately to PU with molecular weight of $15,800 \mathrm{~g} / \mathrm{mol}$ (Table 3, entries 7 and 8). Attempts to use longer reaction time or some other base $(t$-BuOK) or solvent (THF) failed to improve the reactivity of transcarbamoylation (Table 3, entries 9-11).

Based on these optimal reaction conditions, we turned our attention to validate the cycle depolymerization/repolymerization on different PU structures (Table 4, entries 1-5). Five PUs $\mathbf{4 a}-\mathbf{4 e}$ (see the Supporting Information) were synthesized as starting material to screen the applicability of our chemical recycling processes. Depolymerization was performed according to the procedure described in Table 2, and after extraction, the products of depolymerization were used in the repolymerization reaction. Polycondensation was conducted at $130{ }^{\circ} \mathrm{C}$ under catalysis of TBD ( 0.15 equiv per urethane group) in toluene, with 1.1 equiv of monomer 2 . Five different structures of PUs (scaffold corresponding to MDI, 2,6-TDI, 2,4-TDI, HMDI, and HDI) have been evaluated. Because of the high reactivity of the structure 2 a (Table 4 , entry 1 ), the $M_{\mathrm{w}}$ of the repolymerized PU ( $\left.4^{\prime} \mathrm{a}\right)$ provided the best results in our system $\left(M_{\mathrm{w}}=18,100 \mathrm{~g} / \mathrm{mol}\right)$; all structures were able to achieve the original PU structure, although other compounds 
A<smiles>CCCCOC(C)CCCCOC(=O)Nc1ccc(Cc2ccc(NC(=O)OCCCCO)cc2)cc1</smiles>

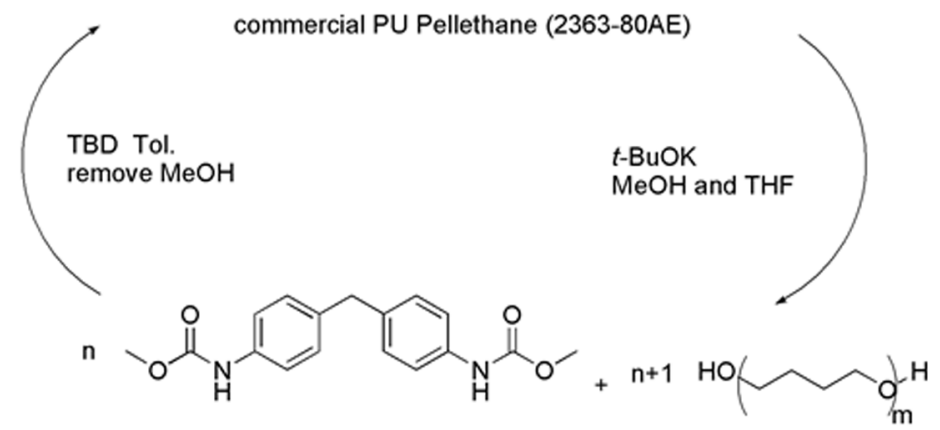

B
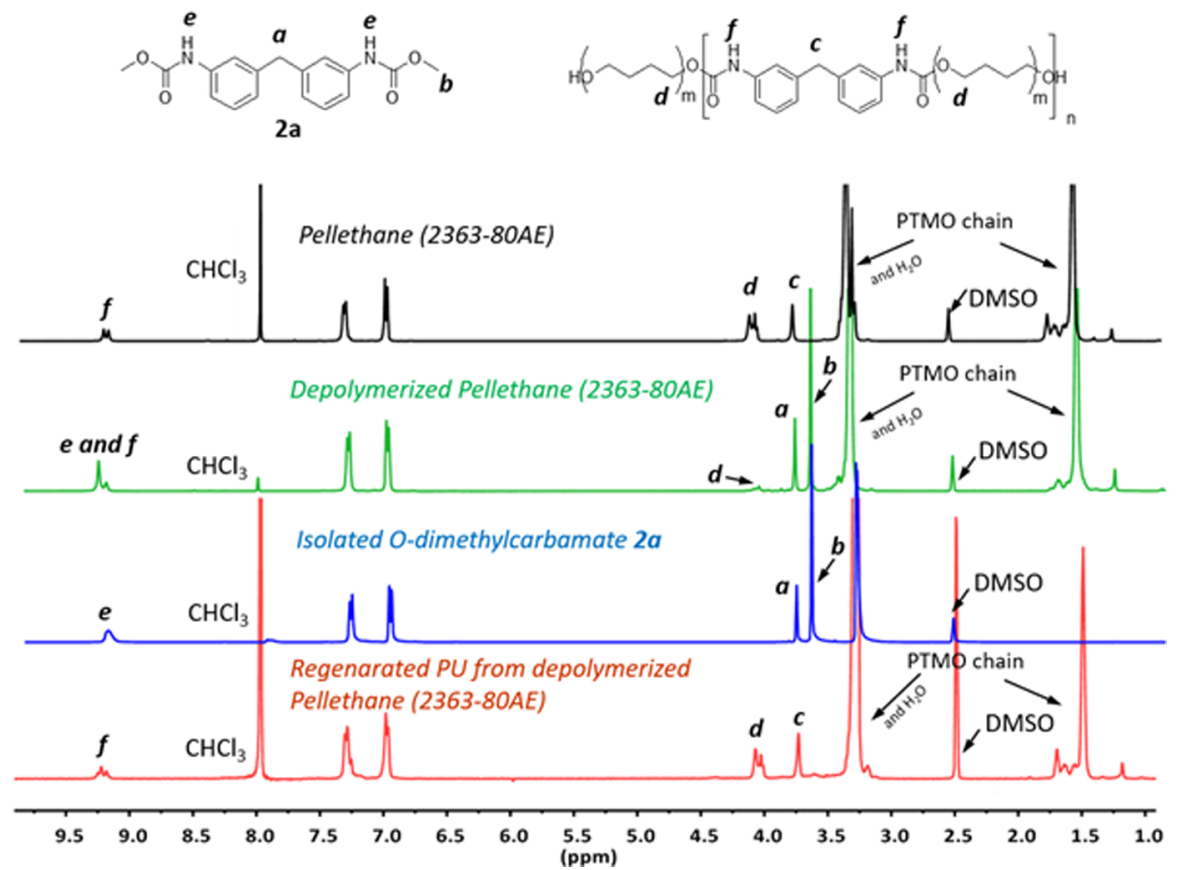

Figure 3. (A) Depolymerization of commercial TPU (Pellethane 2363-80AE) and regeneration of PU. (B) ${ }^{1} \mathrm{H}$ NMR spectra of raw Pellethane 2363-80AE (black), depolymerized Pellethane (green), the isolated O-dimethylcarbamate 2a (blue), and the regenerated PU (red).

$\mathbf{4}^{\prime} \mathbf{b}-\mathbf{4}^{\prime} \mathbf{e}$ were not as remarkable as $4^{\prime} \mathbf{a}\left(\right.$ the $M_{\mathrm{w}}$ are $8900-$ $13,000 \mathrm{~g} / \mathrm{mol})$.

Encouraged by these results, we have extended our investigation to recycle commercial TPU (Pellethane 2363$\left.80 \mathrm{AE}, M_{\mathrm{w}}=110,331 \mathrm{~g} / \mathrm{mol}, M_{\mathrm{w}} / M_{\mathrm{n}}=2.10\right)$. Pellethane was first depolymerized to afford the $O$-dimethylcarbamate $2 \mathrm{a}$ and PTMO (Figure 3A), which can be identified clearly by NMR in the spectrum of the crude of the depolymerization reaction [Figure 3B, ${ }^{1} \mathrm{H}$ NMR spectra of raw Pellethane (black trace), depolymerized Pellethane (green trace), $O$-dimethylcarbamate 2a (blue trace)]. This mixture was then incubated with TBD to regenerate PU successfully [Figure $3 \mathrm{~B}$, crude of the regenerated $\mathrm{PU}$ (red trace)] which was isolated by precipitation $\left(M_{\mathrm{w}}=19,500 \mathrm{~g} / \mathrm{mol}, M_{\mathrm{w}} / M_{\mathrm{n}}=1.40\right)$. Alternatively to this route, the $\mathrm{O}$-dimethylcarbamate 2 a can be isolated due to its stability and possibly converted subsequently into $\mathrm{MDI}^{44,45}$ offering new perspectives to regenerate diisocyanates to feed back into the classical PU industry.

With the aim to recycle PU scraps, we then turned our attention to the PU foams coming from waste electronic and electrical equipment (WEEE; foams from fridge/freezer) as well as construction and demolition waste (foams of insulating panels). Following this strategy, foams were first depolymerized using transcarbamoylation (see the Supporting Information). We can clearly observe in the NMR spectra of the crudes of depolymerization, shown in Figure 4A, the characteristic signals of $O$-methylurethane at $3.62 \mathrm{ppm}$ as well as aromatic signals at 7.1 and $7.3 \mathrm{ppm}$ corresponding to mainly $O$ dimethylcarbamate 2 a originating from $4,4^{\prime}$-MDI-based PU (a major constituent of rigid foam) as well as other aromatic signals associated probably to different possible MDI 
A

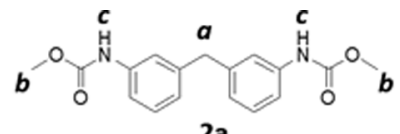

2a

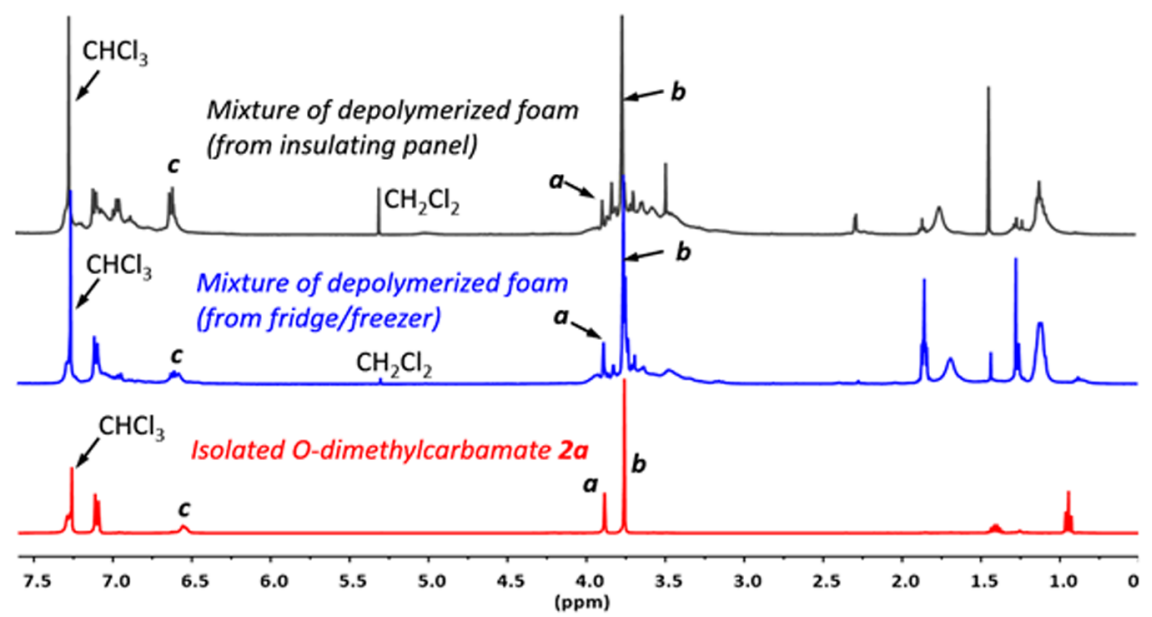

B

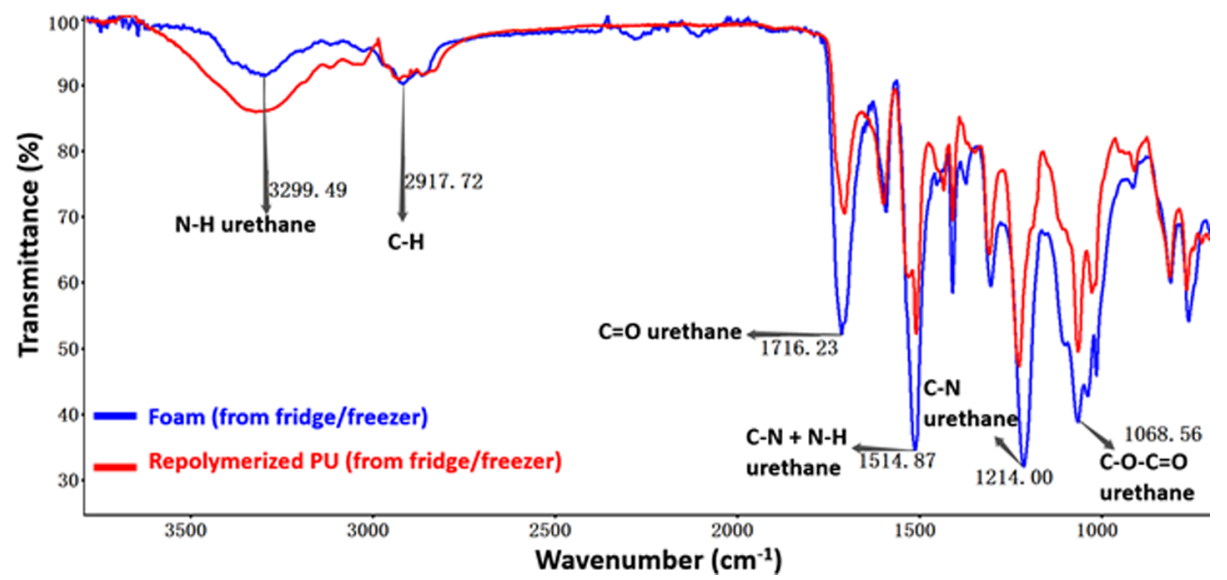

Figure 4. (A) Methanolysis of waste PU. ${ }^{1} \mathrm{H}$ NMR analysis of depolymerized foam (insulating panel, black; fridge/freezer, blue; monomer 2a, red); (B) IR of foam from fridge/freezer (blue) and corresponding regenerated PU (red).

derivatives (isomers, polymeric forms) or aromatic polyols in the case of scrap from insulating panels. Unfortunately, because of the complex composition of the waste foams (e.g., mixtures of polyols, undefined additives: brominated flame retardant, etc.), carbamate $\mathbf{2 a}$ is the only constituent identified by ${ }^{1} \mathrm{H}$ NMR.

The mixture resulting from depolymerization containing carbamates and polyols can then be used to regenerate new PUs. Reconstituted PU was prepared by polycondensation using TBD, starting from depolymerized foams from WEEE and removing unpolymerized materials and unincorporated substances after precipitation, PU was obtained, with characteristic signals in IR spectrum (Figure 4B).

Alternatively in the case of a more complicated mixture of depolymerization (foams of insulating panel), because of too much uncertain compositions in some rigid foams ${ }^{46-48}$ (e.g., polymeric MDI, undefined PUs; mixture of polyols, brominated flame retardant; catalysts; salts...), purification is preferred by the isolation of the carbamate $\mathbf{2} \mathbf{a}$ with a yield of
$16 \%$ (wt \%) that could be further reformulated or further transformed into diisocyanates, associated to the classical recovery of polyols done in glycolysis for example.

\section{CONCLUSIONS}

In this report, a new chemical recycling process of PU (TPU and PU foams) is presented based on the transcarbamoylation reaction. PUs are depolymerized under mild and efficient conditions using a base and THF/MeOH as the solvent at 65 ${ }^{\circ} \mathrm{C}$ to provide quantitatively polyols and $\mathrm{O}$-dimethylcarbamates making this strategy simple and easy to scale up. It is also noteworthy that THF can be substituted by $\mathrm{MeOH}$ offering great prospects. The obtention of $\mathrm{O}$-dimethylcarbamates makes this strategy also very attractive since this intermediate is able to react with polyols to regenerate PUs using transcarbamoylation releasing $\mathrm{MeOH}$. The reactivity of this intermediate also offers huge versatility in the outputs of this strategy since the mixture obtained from depolymerization can be used directly to regenerate new PUs through polyconden- 
sation or by modifying the formulation (e.g., by adding polyols) to rectify or confer new properties or performances to the regenerated PU. ${ }^{49}$ Alternatively, each constituent resulting from depolymerization can be isolated, particularly the $O$ dimethylcarbamates which due to their stability can be further reacted to synthesize new PUs (nonisocyanate routes) ${ }^{49}$ or converted to diisocyanates to be fed back into the classical PU industry to generate virgin PUs. The last route is of interest in the case of the composition of PUs that is not suitable for the market or does not satisfy new regulations due to the presence of toxic substances (e.g., brominated flame retardant).

\section{ASSOCIATED CONTENT}

\section{(s) Supporting Information}

The Supporting Information is available free of charge at https://pubs.acs.org/doi/10.1021/acsomega.0c04855.

Experimental procedures and characterization data, ${ }^{1} \mathrm{H}$ NMR spectra of compounds, and gel permeation chromatography (PDF)

\section{AUTHOR INFORMATION}

\section{Corresponding Author}

Vincent Semetey - Chimie ParisTech, PSL University, CNRS, Institut de Recherche de Chimie Paris, 75005 Paris, France; (1) orcid.org/0000-0001-8939-2538; Phone: +33 (0)1 85

7842 65; Email: vincent.semetey@chimieparistech.psl.eu

Author

Liang Zhao - Chimie ParisTech, PSL University, CNRS, Institut de Recherche de Chimie Paris, 75005 Paris, France

Complete contact information is available at:

https://pubs.acs.org/10.1021/acsomega.0c04855

\section{Notes}

The authors declare no competing financial interest.

\section{ACKNOWLEDGMENTS}

L.Z. thanks the China Scholarship Council for the financial support. The authors are grateful to the Institut de Recherche de Chimie Paris (IRCP), the Centre National de la Recherche Scientifique (CNRS), and Chimie ParisTech for the facilities and the administrative support. Xavier Lantoinette and Marianne Fleury from ecosystem (French take-back scheme) are acknowledged for providing $\mathrm{PU}$ foam wastes from appliances as well as helpful discussion. The authors also thank Chaire Mines Urbaines and Fondation ParisTech for their support.

\section{REFERENCES}

(1) Cornille, A.; Auvergne, R.; Figovsky, O.; Boutevin, B.; Caillol, S. A perspective approach to sustainable routes for non-isocyanate polyurethanes. Eur. Polym. J. 2017, 87, 535-552.

(2) Zia, K. M.; Bhatti, H. N.; Ahmad Bhatti, I. Methods for polyurethane and polyurethane composites, recycling and recovery: A review. React. Funct. Polym. 2007, 67, 675-692.

(3) Behrendt, G.; Naber, B. The chemical recycling of polyurethane. J. Univ. Chem. Technol. Metall. 2009, 44, 3-23.

(4) DeGaspari, J. From trash to cash. Mech. Eng. 1999, 121, 48-51.

(5) Campbell, G. A.; Meluch, W. C. Polyurethane foam recycling. Superheated steam hydrolysis. Environ. Sci. Technol. 1976, 10, 182185.
(6) Dai, Z.; Hatano, B.; Kadokawa, J.-I.; Tagaya, H. Effect of diaminotoluene on the decomposition of polyurethane foam waste in superheated water. Polym. Degrad. Stab. 2002, 76, 179-184.

(7) Nikje, M. M. A.; Nikrah, M.; Mohammadi, F. H. A. Microwaveassisted polyurethane bond cleavage via hydroglycolysis process at atmospheric pressure. J. Cell. Plast. 2008, 44, 367-380.

(8) Xue, S.; Omoto, M.; Hidai, T.; Imai, Y. Preparation of epoxy hardeners from waste rigid polyurethane foam and their application. $J$. Appl. Polym. Sci. 1995, 56, 127-134.

(9) Van Der Wal, H. R. New chemical recycling process for polyurethanes. J. Reinf. Plast. Compos. 1994, 13, 87-96.

(10) Chuayjuljit, S.; Norakankorn, C.; Pimpan, V. Chemical recycling of rigid polyurethane foam scrap via base catalyzed aminolysis. J. Met., Mater. Miner. 2002, 12, 19-22.

(11) Datta, J.; Włoch, M. Recycling of polyurethanes. In Polyurethane Polymers: Blends and Interpenetrating Polymer Networks; Thomas, S., Datta, J., Reghunathan, A., Haponiuk, J., Eds.; Elsevier: Amsterdam, 2017; pp 323-358.

(12) Mitova, V.; Grancharov, G.; Molero, C.; Borreguero, A. M.; Troev, K.; Rodriguez, J. F. Chemical degradation of polymers (polyurethanes, polycarbonate and polyamide) by esters of $\mathrm{H}$ phosphonic and phosphoric acids. J. Macromol. Sci., Part A: Pure Appl. Chem. 2013, 50, 774-795.

(13) Troev, K.; Tsekova, A.; Tsevi, R. Chemical degradation of polyurethanes 2 . Degradation of flexible polyether foam by dimethyl phosphonate. Polym. Degrad. Stab. 2000, 67, 397-405.

(14) Troev, K.; Grancharov, G.; Tsevi, R.; Tsekova, A. A novel approach to recycling of polyurethanes: chemical degradation of flexible polyurethane foams by triethyl phosphate. Polymer 2000, 41, $7017-7022$.

(15) Troev, K.; Grancharov, G.; Tsevi, R. Chemical degradation of polyurethanes 3. Degradation of microporous polyurethane elastomer by diethyl phosphonate and tris(1-methyl-2-chloroethyl) phosphate. Polym. Degrad. Stab. 2000, 70, 43-48.

(16) Troev, K.; Atanasov, V.; Tsevi, R.; Grancharov, G.; Tsekova, A. Chemical degradation of polyurethanes. Degradation of microporous polyurethane elastomer by dimethyl phosphonate. Polym. Degrad. Stab. 2000, 67, 159-165.

(17) Troev, K.; Atanassov, V.; Tzevi, R. Chemical degradation of polyurethanes. II. Degradation of microporous polyurethane elastomer by phosphoric acid esters. J. Appl. Polym. Sci. 2000, 76, 886-893.

(18) Troev, K.; Tsekova, A.; Tsevi, R. Chemical degradation of polyurethanes: Degradation of flexible polyester polyurethane foam by phosphonic acid dialkyl esters. J. Appl. Polym. Sci. 2000, 78, 25652573.

(19) Grancharov, G.; Mitova, V.; Shenkov, S.; Topliyska, A.; Gitsov, I.; Antonya, G. T.; Ivan Troev, K. Smart polymer recycling: Synthesis of novel rigid polyurethanes using phosphorus-containing oligomers formed by controlled degradation of microporous polyurethane elastomer. J. Appl. Polym. Sci. 2007, 105, 302-308.

(20) Gerlock, J.; Braslaw, J.; Zinbo, M. Polyurethane waste recycling. 1. Glycolysis and hydroglycolysis of water-blown foams. Ind. Eng. Chem. Process Des. Dev. 1984, 23, 545-552.

(21) Wu, C.-H.; Chang, C.-Y.; Cheng, C.-M.; Huang, H.-C. Glycolysis of waste flexible polyurethane foam. Polym. Degrad. Stab. 2003, 80, 103-111.

(22) Schulzke, T.; Iakovleva, A.; Cao, Q.; Conrad, S.; Zabelkin, S.; Grachev, A. Polyurethane foams produced from pyrolysis oilProduction and possible application. Biomass Bioenergy 2018, 115, 195-202.

(23) Wu, J.; Wang, Y.; Wan, Y.; Lei, H.; Yu, F.; Liu, Y.; Chen, P.; Yang, L.; Ruan, R. Processing and properties of rigid polyurethane foams based on bio-oils from microwave-assisted pyrolysis of corn stover. Int. J. Agric. Biol. Eng. 2009, 2, 40-50.

(24) Al-Salem, S. M.; Lettieri, P.; Baeyens, J. Recycling and recovery routes of plastic solid waste (PSW): A review. Waste Manage. 2009, $29,2625-2643$. 
(25) Borda, J.; Pásztor, G.; Zsuga, M. Glycolysis of polyurethane foams and elastomers. Polym. Degrad. Stab. 2000, 68, 419-422.

(26) Wu, C.-H.; Chang, C.-Y.; Li, J.-K. Glycolysis of rigid polyurethane from waste refrigerators. Polym. Degrad. Stab. 2002, $75,413-421$.

(27) Molero, C.; de Lucas, A.; Rodríguez, J. F. Recovery of polyols from flexible polyurethane foam by "split-phase" glycolysis with new catalysts. Polym. Degrad. Stab. 2006, 91, 894-901.

(28) Molero, C.; de Lucas, A.; Rodríguez, J. F. Recovery of polyols from flexible polyurethane foam by "split-phase" glycolysis: Glycol influence. Polym. Degrad. Stab. 2006, 91, 221-228.

(29) Simón, D.; García, M. T.; de Lucas, A.; Borreguero, A. M.; Rodríguez, J. F. Glycolysis of flexible polyurethane wastes using stannous octoate as the catalyst: Study on the influence of reaction parameters. Polym. Degrad. Stab. 2013, 98, 144-149.

(30) Asahi, N.; Sakai, K.; Kumagai, N.; Nakanishi, T.; Hata, K.; Katoh, S.; Moriyoshi, T. Methanolysis investigation of commercially available polyurethane foam. Polym. Degrad. Stab. 2004, 86, 147-151. (31) Liu, L.; Tang, L.; Wu, Y.; Ni, Y.; Zhu, Z. Degradation process investigation of thermoplastic polyurethane elastomer in supercritical methanol. Polym. Degrad. Stab. 2013, 98, 2520-2528.

(32) Deepa, P.; Jayakannan, M. Solvent-free and nonisocyanate melt transurethane reaction for aliphatic polyurethanes and mechanistic aspects. J. Polym. Sci., Part A: Polym. Chem. 2008, 46, 2445-2458.

(33) Rokicki, G.; Piotrowska, A. A new route to polyurethanes from ethylene carbonate, diamines and diols. Polymer 2002, 43, 29272935.

(34) Shapiro, G.; Marzi, M. Facile and selective $O$-alkyl transesterification of primary carbamates with titanium(IV) alkoxides. J. Org. Chem. 1997, 62, 7096-7097.

(35) Jousseaume, B.; Laporte, C.; Toupance, T.; Bernard, J. M. Investigations in the catalytic species of the distannoxane-catalyzed transcarbamoylation. Tetrahedron Lett. 2003, 44, 5983-5985.

(36) Dumrul, H.; Yuksel, F. Synthesis and characterization of novel symmetrical and asymmetrical substituted $\mathrm{Zn}$ (II) phthalocyanines. Polyhedron 2013, 63, 83-90.

(37) Jousseaume, B.; Laporte, C.; Toupance, T.; Bernard, J.-M. Efficient bismuth catalysts for transcarbamoylation. Tetrahedron Lett. 2002, 43, 6305-6307.

(38) Rhoné, B.; Semetey, V. Base-catalyzed transcarbamoylation. Synlett 2017, 28, 2004-2007.

(39) Isaksson, R.; Kumpiņa, I.; Larhed, M.; Wannberg, J. Rapid and straightforward transesterification of sulfonyl carbamates. Tetrahedron Lett. 2016, 57, 1476-1478.

(40) Maisonneuve, L.; Lamarzelle, O.; Rix, E.; Grau, E.; Cramail, H. Isocyanate-free routes to polyurethanes and poly(hydroxy urethane)s. Chem. Rev. 2015, 115, 12407-12439.

(41) Unverferth, M.; Kreye, O.; Prohammer, A.; Meier, M. A. R. Renewable non-isocyanate based thermoplastic polyurethanes via polycondensation of dimethyl carbamate monomers with diols. Macromol. Rapid Commun. 2013, 34, 1569-1574.

(42) Firdaus, M.; Meier, M. A. R. Renewable polyamides and polyurethanes derived from limonene. Green Chem. 2013, 15, 370380.

(43) Kébir, N.; Nouigues, S.; Moranne, P.; Burel, F. Nonisocyanate thermoplastic polyurethane elastomers based on poly(ethylene glycol) prepared through the transurethanization approach. J. Appl. Polym. Sci. 2017, 134, 44991.

(44) Uriz, P.; Serra, M.; Salagre, P.; Castillon, S.; Claver, C.; Fernandez, E. A new and efficient catalytic method for synthesizing isocyanates from carbamates. Tetrahedron Lett. 2002, 43, 1673-1676.

(45) Kreye, O.; Mutlu, H.; Meier, M. A. R. Sustainable routes to polyurethane precursors. Green Chem. 2013, 15, 1431-1455.

(46) Kairyte, A.; Vejelis, S. Evaluation of forming mixture composition impact on properties of water blown rigid polyurethane (PUR) foam from rapeseed oil polyol. Ind. Crops Prod. 2015, 66, 210-215.
(47) Polyurethane Handbook: Chemistry, Raw Materials, Processing, Application, Properties; Oertel, G., Abele, L., Eds.; Hanser, Macmillan: USA, 1994.

(48) Fleurent, H.; Thijs, S. The use of pentanes as blowing agent in rigid polyurethane foam. J. Cell. Plast. 1995, 31, 580-599.

(49) Ye, S.; Xiang, X.; Wang, S.; Han, D.; Xiao, M.; Meng, Y. Nonisocyanate $\mathrm{CO}_{2}$-based poly(ester-co-urethane)s with tunable performances: A potential alternative to improve the biodegradability of PBAT. ACS Sustainable Chem. Eng. 2020, 8, 1923-1932. 